Asen O. Ivanov

$\mathrm{PhD}$ Candidate

Faculty of Information (iSchool)

University of Toronto

\title{
Bridging the Gap: The Concept of Information in the Work of Marcia J. Bates and Birger Hjørland (Paper)
}

\begin{abstract}
:
This paper presents an analysis of the debate over the concept of information between Marcia J. Bates and Birger Hjørland. To this end, the paper provides an overview of the Bates-Hjørland debate and places it in a historical context. It then outlines a research perspective that does not resolve the debate but instead, pragmatically, circumvents it.
\end{abstract}

\section{Résumé:}

Cet article présente une analyse conceptuelle du débat entre Marcia J. Bates et Birger Hjørland sur le concept d'information. À cette fin, l'article présente un résumé du débat de Bates-Hjørland et le positionne ensuite dans une perspective historique. Enfin, il décrit une perspective de recherche qui ne résout pas le débat, mais, de façon pragmatique, le contourne. 


\section{An overview of the Bates-Hjørland debate}

In 2005 and 2006, Marcia Bates published two articles that offer an integrative objective and subjective definitions of the concept of information. Building on Edwin B. Parker's (1974) postulate that information is the "pattern of organization of matter and energy," Bates (2005; 2006) argues that patterns of organization exist objectively in the material world, and further proposes that these objective patterns of organization are identified, selected, processed and stored cognitively by living beings. The gist of Bates' argument is that by identifying and selecting patterns in the physical world, human beings integrate new information with their preexisting knowledge and thus create new knowledge, which in turn takes the form of neural patterns in their brains (Bates 2005). To formalize this idea Bates $(2006,1042)$ postulates a twindefinition of information:

- Information 1: The pattern of organization of matter and energy.

- Information 2: Some pattern of organization of matter and energy given a meaning by a living being.

Information 1 is an objective, material information (e.g., as manifested in writing, speech or other patterns), whereas Information 2 is a subjective, semantic information that has been selected; cognitively processed and stored; and given meaning by a living being. Importantly, in this conceptualization of information, "no abstract plane is assumed to house or manifest information ... information resides in the physical realities of nature, whether in the structure of a piece of granite, or in the neural pathways of the brain" (Bates 2005). What Bates does not address in detail, however, is the extent to which non-observable, extra-logical social and cultural factors may or may not filter into how Information 1 is cognitively processed and given meaning to become Information 2. In other words, by downplaying the causal effects of the sociocultural context within which information, meaning, and knowledge are unavoidably 
steeped, Bates emphasizes the ontological dimension of the concept of information at the expense of its epistemological dimension.

It is precisely on those lines that Bates' conceptualization of information has elicited a strong response from Birger Hjørland (2007), who has questioned the overall integrity of her position by rejecting the validity of an objective definition of information (1449-1450).

Hjørland's contention is not that objective reality does not exist, a fact he considers a commonsense knowledge (Hjørland 2004). Rather, he argues that physical and material patterns should not be considered information per se because they acquire the status of information only within a given sociocultural context. In this perspective, information emerges within "knowledge-domains" and "discourse communities" and always in relation to addressing a specific information need - the point being that "to consider something information is thus always to consider it as informative in relation to some possible questions" and within a broader sociocultural framework of meanings (Hjørland 2007, 1451; For an overview see Hjørland and Albrechtsen 1995). As Hjørland (2009) explains, it may very well be the case that information is often inscribed in material artifacts and conveyed through speech or gestures but "the physical stuff in itself is not information until it is used as a [semiotic] sign" (643). Information, as such, Hjørland (2007) argues is always a subjective/situational phenomenon - that is to say, an epistemological rather than an ontological concept.

In the final analysis, the disagreement between Bates and Hjørland can be condensed to their conceptions of information: (1) as an objective entity that gives rise to subjective processes (as per Bates) or (2) as a subjective process that imposes meaning on objective entities (as per Hjørland). 


\section{The Bates-Hjørland debate from a historical perspective}

Strictly speaking, neither of the two positions is new to information science. In fact, the objective/subjective split in conceptualizing information can be traced back to the origins of the field in the ideas of the leading figures of the documentation movement and contemporary library science. The central goal of Paul Otlet's work, the preeminent thinker of the documentation movement, was to develop a method of extracting the unique pieces of knowledge - what he called "facts" — contained in documents in order to make their organization and retrieval more efficient (Otlet 1990, 204-207). Otlet viewed information as a stable objective entity that could be organized and interpreted irrespective of the sociocultural context within which it exists (See, Rayward 1994, 247-249; Rieusset-Lemarie 1997, 303). On the other end of the spectrum, we can locate the work of Margaret Egan and Jesse Shera, two preeminent library science thinkers, who sought to shift the focus of library practices away from the individual use of books to the wider societal implications of the dissemination of information (Egan and Shera 1952, 132). As John Budd (2002) points out, a crucial aspect of Egan and Shera's thinking is that knowledge is created by the selective filtering of information through a wider sociocultural framework of meanings and that as such all "knowledge is situated, and therefore has a social element" (95).

\section{A flank movement around the objective/subjective gap}

Considering the enduring legacy of this debate, in concluding this paper, I wish to propose how we can productively address it. This is important because we have good reasons to suppose that both an objective and subjective definitions of information are valid and necessary for the goals of information research. Bates acknowledges this as evinced by her integrative definition of 
information that accounts for both objective information (Information 1) and subjective information (Information 2). And while Hjørland rejects the necessity of an objective definition of information in his exchange with Bates, he has also acknowledged, albeit years earlier, that information has objective properties. Writing in 1992, Hjørland notes that the objective properties of a document constitute a theoretical problem because: "On the one hand, naturally, documents reflect the author's subjective view of the subjects treated. On the other hand, the document has objective properties ... [therefore] if a document states that a person's intelligence is correlated with the size of his brain, this is a subjective (and false) judgment. But it is an objective fact that this document contains this (false) judgment" (Hjørland 1992, 182). The problem Hjørland encounters in this thought experiment is that the objective properties of a document carry an ontological weight that defines its identity independently from any given subjective/situational interpretation.

Considering the above, I argue that the gap between the objective and subjective definition of information could be bridged through a flank movement that shifts the analytical focus away from ontological or epistemological debates and places it on pragmatist philosophical foundations (Muniesa 2005). Such an analytical move to conceptualizing social phenomena has been highly-productive across the social sciences over the last three decades, where it has been popularized under the label of practice theory. ${ }^{\mathrm{i}}$ Its prime analytical utility being that it integrates objective and subjective dimensions of social life onto a single theoretical unit of analysis, namely, onto social practices. Understanding the latter to be:

[W]ays of acting and interacting that appear within particular communities or groups; depend on shared presuppositions and assumptions; often have a significant corporeal or material dimension; and unfold in individuals' lives as a result of active, creative, and 
less than fully conscious putting into play of those presuppositions and assumptions in the context of various and intersecting socio-biographical and interactional exigencies.

(Gross 2009, 365)

Many of the fundamental insights of practice theory are already explicitly or implicitly integrated in the domain-analysis approach (Hjørland and Albrechtsen 1995) as well as in various approaches associated with the information practice "umbrella concept" (Savolainen 2007). But I argue that practice theory is distinctive, because while domain-analysis and information practice approaches tend to be characterized by a strong social-constructionist predilection, practice theory approaches acknowledge in much greater depth the constraints social and material forces impose on social practices-bringing into analytical focus the extent to which "objective conditions constrain social constructions" (Zuckerman 2012). An emphasis on practice in information research, thus, would enable us to follow the "red thread of information" (Bates 1999) in the social world by switching between theoretical concepts to examine the extent to which the objective properties of information and subjective/situational interpretations come together differently in different contexts and at different times. The objective/subjective gap as such effectively disappears because "to say of something that it is done subjectively or objectively is less mutually exclusive than to say that it is subjective or objective" (Muniesa 2012, 25 [emphasis in the original]). Practice theory approaches have gained momentum across the social sciences precisely because of their capacity of "transcending the macro-objectivist and micro-subjectivist levels of analysis", and recent work indicates that such approaches could play an important role in information science too (Huizing and Cavanagh 2011). 


\section{Reference List}

Bates, Marcia J. 1999. "The invisible substrate of information science." Journal of the Association for Information Science and Technology 50 (12): 1043-1050.

. 2005. "Information and knowledge: An evolutionary framework for information science." Information Research 10 (4). URL: http://www.informationr.net/ir/104/paper239.html

- 2006. "Fundamental forms of information." Journal of the American Society for Information Science and Technology 57 (8): 1033-1045.

Budd, John M. 2002. “Jesse Shera, Social Epistemology and Praxis.” Social Epistemology 16 (1): 93-98.

Egan, Margaret E. and Jesse H. Shera. 1952. "Foundations of a Theory of Bibliography." The Library Quarterly 22 (2): pp. 125-137.

Gherardi, Silvia. 2009. "Introduction: The critical power of the practice lens." Management Learning 40 (2): 115-128.

Gross, Neil. 2009. "A pragmatist theory of social mechanisms.” American Sociological Review 74 (3): 358-379.

Hjørland, Birger and Hanne Albrechtsen. 1995. "Toward a new horizon in information science: domain-analysis." Journal of the Association for Information Science and Technology 46 (6): 400-425.

Hjørland, Birger. 1992. "The concept of 'subject' in information science." Journal of Documentation 48 (2): 172-200.

. 2004. "Arguments for philosophical realism in library and information science." Library Trends 52 (3): 488-506.

_ 2007 "Information: Objective or subjective/situational?" Journal of the Association for Information Science and Technology 58 (10): 1448-1456.

- 2009. "The controversy over the concept of information: A rejoinder to Professor Bates.” Journal of the Association for Information Science and Technology 60 (3): 643-643.

Huizing, Ard, and Mary Cavanagh. 2011. "Planting contemporary practice theory in the garden of information science.” Information Research 16 (4). URL: http://InformationR.net/ir/164/paper497.html 
Lamont, Michèle. 2012. "Toward a comparative sociology of valuation and evaluation." Annual Review of Sociology 38: 201-221.

Muniesa, Fabian. 2012. "A flank movement in the understanding of valuation." The Sociological Review 59 (2): 24-38.

Orlikowski, Wanda J. 2007. "Sociomaterial practices: Exploring technology at work." Organization Studies 28 (9): 1435-1448.

Otlet, Paul. 1990. International Organisation and Dissemination of Knowledge: Selected Essays of Paul Otlet. Translated and edited by W. Boyd Rayward. Amsterdam: Elsevier.

Parker, Edwin B. 1974. "Information and Society." In Library and Information Service Needs of the Nation: Proceedings of a Conference on the Needs of Occupational, Ethnic and Other Groups in the United States." Washington, DC, U.S.G.P.O.

Rayward, W. Boyd. 1994. "Visions of Xanadu: Paul Otlet (1868-1944) and Hypertext." Journal of the Association for Information Science and Technology 45 (4): 235-250.

Rieusset-Lemarie, Isabelle. 1997. "P. Otlet's Mundaneum and the International Perspective in the History of Documentation and Information Science." Journal of the Association for Information Science and Technology 48 (4): 301-309.

Savolainen, Reijo. 2007. "Information Behavior and Information Practice: Reviewing the 'Umbrella Concepts' of Information-Seeking Studies." The Library Quarterly: Information, Community, Policy 77 (2): 109-132.

Zuckerman, Ezra W. 2012. "Construction, concentration, and (dis) continuities in social valuations." Annual Review of Sociology 38: 223-245.

\section{Notes}

\footnotetext{
${ }^{\mathrm{i}}$ In this paper, I draw predominantly on pragmatist ideas as developed and applied in the context of the sociology of valuation and evaluation. Practice theory perspectives are being implemented across many other academic disciplines, and are particularly prominent in organizational studies (e.g., Orlikowski 2007; Gherardi 2009). Yet, I believe that the sociology of valuation and evaluation provides a more directly relatable heuristic example for information science because as a field of inquiry it is centered on examining the ambiguous concept of value across diverse social domains and contexts of practice (See, Lamont 2012).
} 